\title{
O DESIGN GRÁFICO NA REVISTA ILLUSTRAÇÃO PARANAENSE (1927-1930/33): uma aproximação coerente
}

\author{
Carla Cristina Vasconcelos Batista \\ Programa de Pós-Graduação em Design, PPGDesign - UFPR \\ carlacvb7@gmail.com \\ Ronaldo de Oliveira Corrêa \\ Programa de Pós-Graduação em Design, PPGDesign - UFPR \\ rcorrea@ufpr.br
}

\begin{abstract}
Resumo: O presente artigo promove uma aproximação do campo do design gráfico com as capas da revista Illustração Paranaense de 1927 a 1930/33, uma vez que esta se trata de um periódico bastante reconhecido como difusor do movimento Paranismo ocorrido no Estado do Paraná. Para isso, foi feito primeiramente um mapeamento das revistas nos acervos públicos de Curitiba para, posteriormente, ser realizada a análise da imagem constituinte da capa da revista. Dessa forma, a mensagem visual evocada é construída a partir de ferramentas e signos diferentes que favorecem a mensagem plástica para entender sua significação com relação da interpretação que se dá aos elementos compositivos e a influência conotativa do paranista.
\end{abstract}

Palavras-chave: Illustração Paranaense, Paranismo e design gráfico.

\begin{abstract}
This present article provides an approach of the graphic design with the covers of the 'Illustração Paranaense' magazine, 1927-1930/33, as this it is a well recognized periodical known as the difusser of 'Paranismo' movement in the State of Paraná. For this, was first made a mapping of magazines in public collections in Curitiba, subsequently, analysis of constituent image of the cover of the magazine. Therefore, the visual evoked message is built from diferente tools and signs that favor message to understand its plastic end connotative meaning with regard the interpretation that gives the elements compositive and the influence of connotative paranista.
\end{abstract}

Keyworks: Illustração Paranaense, Paranismo and graphic design.

\section{INTRODUÇÃO}

A revista "Illustração Paranaense" foi um porta-voz do movimento Paranista que promovia a criação de uma identidade cultural distinta de São Paulo e do país. As capas 
analisadas dessa revista favorecem perceber a história social do design no Estado do Paraná, uma vez que esta revista circulava por todo Estado, principalmente na capital, Curitiba. Diante da sua relevância literária e da promoção aos leitores "paranistas" pretende-se relacionar imagem e texto numa perspectiva da área do design gráfico ${ }^{1}$ para visualizar a mensagem visual que as capas transmitem.

O objetivo do texto prevê a reconstrução da memória gráfica através de uma análise visual das capas da revista Illustração Parananense que circulou no Estado do Paraná no período de 1927 a 1930/33. Vale ressaltar que foram analisadas 2 capas (figura 2) das 31 que se encontram na linha do tempo no apêndice do artigo. Para análise foi necessário fazer um levantamento do contexto histórico que circunda a Revista Illustração Paranaense a partir da difusão do movimento Paranista até seu encerramento em 1930. Assim, apresentar as capas da Revista Illustração Paranaense, de modo a mostrar a prática projetual prevista no design gráfico e fazer uma análise da imagem que corresponde as alterações das capas ao longo das suas edições.

Os procedimentos adotados consistiram no método histórico cujo foco está na investigação de acontecimentos do passado, permitindo olhar o contexto cultural de um dado período (PRODANOV, 2013). Foi mapeado os acervos públicos da cidade de Curitiba, PR, que possuíam as Revistas Illustração Paranaense a fim de entender como foram organizadas no sistema de catalogação e coletadas as capas das edições da Revista desde sua criação em 1928 a 1930 e 1933 com sua reedição. Para compreender o arquivamento do periódico como Obra rara nos acervos foram entrevistadas as bibliotecárias da Biblioteca Pública do Paraná, da Casa da Memória e do Museu Paranaense. Estas contribuíram para a construção histórica da revista, permitindo acesso à fonte primária do movimento Paranismo e outras obras que dizem respeito à ilustração da capa da Revista Illustração Paranaense.

A estratégia utilizada visa uma aproximação que traz à discussão a construção da imagem produzida na composição do layout da capa e, assim, interpretar a mensagem visual. Com ferramentas diferentes e variados tipos de signos (plásticos, icônicos e linguísticos) pode-se obter uma significação da imagem, tendo em vista seu caráter polissêmico (JOLY, 1996). Visto que a revista está inserida num contexto cultural e histórico procura-se estabelecer uma relação com o movimento Paranismo proposta pelos intelectuais e os artistas de Curitiba na busca por uma identidade cultural. Tal fator apresenta esses atores que intervêm direta ou indiretamente com os significados denotativos e conotativos da imagem. Enfim, a mensagem visual impregnada nas capas da Revista Illustração Paranaense apresenta uma série de indícios que apresentam as noções do design gráfico desde os signos utilizados na ilustração principal da capa até a tipografia utilizada para definir um tipo de logotipo da revista. No que tange as iconografias do Paranismo, serão analisadas somente as que aparecem na capa da revista e não do movimento, de modo geral.

\footnotetext{
1 O design gráfico é um processo técnico e criativo que utiliza imagens e textos para comunicar mensagens, idéias e conceitos, com objetivos comerciais ou de fundo social. (Disponível em: <http://www.adg.org.br/adgbrasil.php> acesso: 13/11/2013)
} 


\section{A REVISTA “ILLUSTRAÇÃO PARANAENSE"}

A revista "Illustração Paranaense: Mensário Paranista de Arte e Actualidades" foi um periódico mensal destinado ao público paranaense e teve maior alcance com os ideários paranistas na própria capital, Curitiba. O fundador deste mensário foi João Batista Groff, diretor da revista, cineasta, fotógrafo e pintor, bastante influente na elite da sociedade curitibana. Este, por sua vez, convidou João Turin, artista e escultor animalista de bastante destaque na sociedade, para ilustrar a capa da revista. Por se tratar de uma revista que expressava o Paranismo, um movimento político e cultural na construção de uma identidade para o Paraná, será apresentado também o contexto histórico.

Segundo Batistella (2012), o Paranismo teve início após a emancipação do Estado do Paraná em relação a São Paulo, em 1853, sendo o resultado de um reflexo da autoimagem do Estado do Paraná na busca por uma identidade local que se distinguisse de São Paulo e, inclusive, do restante do país. Nessa perspectiva, "as elites intelectuais e políticas do final do século XIX, empenharam-se na invenção de uma tradição paranaense" (2012, p.02). O principal propagador dos ideários do Paranismo foi o jornalista e historiador Alfredo Romário Martins (BATISTELLA, 2012). Este escreveu o livro chamado História do Paraná (1899) considerada, posteriormente, como História Oficial do Paraná diante do rigor científico, reforçando a construção de uma identidade cultural própria do Estado. Entretanto, Romário Martins e demais intelectuais do Paranismo foram influenciados pelo conceito de "meio e raça" que diz respeito à questão da miscigenação que romantizava a presença do índio e esquecia o negro africano como ancestral (BATISTELLA, 2012). Justamente porque a presença dessas raças ameaçava o processo civilizatório. Em contrapartida, isso significava o processo de "branqueamento" da população que excluía o negro, o índio e o mestiço da história. Ainda existiam os imigrantes europeus que inicialmente foram vistos pelos paranistas como uma ameaça ao projeto identitário que vinha sendo construído.

Em 1927, o movimento Paranista ganhou maturidade que levou a concepção de um Centro Paranista em Curitiba. Entretanto, o que vem significar paranista? Segundo diálogo retirado do periódico A Divulgação (Fev-Mar, 1948) "o substantivo Paranista fora lançado em 1906, por Domingos Nascimento com a significação "material do Paraná", tomado de amor "erange" pelo Estado, por cujo progresso, prestígio e integridade envolvida todos os aspectos". Neste caso, o Centro Paranista foi criado para reunir as pessoas num determinado lugar para que pudessem pensar na formação identitária do Estado, pois "a ideia é criar um espírito e um sentimento Paranista, isto é, devotados ao Paraná propício ao desenvolvimento do Estado em todos os rumos do seu progresso e civilização" (A divulgação, Fev-Mar, 1948). Isso significava que o paranista não precisava ser necessariamente um paranaense, mas sim aquele que se afeiçoasse a terra caracterizada pela sociedade e que pudesse trazer contribuições significantes para o desenvolvimento moral, intelectual e material.

No mesmo ano, João Batista Groff lança a revista Illustração Paranaense, no intuito de propagar o movimento Paranista. Aproveita a oportunidade ao se integrar na elite paranaense conseguindo a colaboração de intelectuais e artistas do Paraná na constituição da revista (PILOTTO, 1976, p. 51). A proposta da revista voltava-se a 
assuntos de literatura, artes plásticas, música, história, comportamento, moda, perfis de personalidades, locais, cinema, embora seu discurso por trás dessas informações estivesse embutido os ideais do Paranismo (ARAÚJO, 2012). Segundo Batistella, apesar do curto período de existência, a revista serviu para "consolidação do paranismo no imaginário dos paranaenses" (2012, p.9). Para uso de uma imagem que identificasse o lugar, a paisagem em si, foi eleita pelo Paranismo "o pinheiro e o pinhão", símbolos identitários do Estado que são considerados até hoje iconografias do Paraná. Dessa forma, há um destaque na capa da revista Ilustração Paranaense com a ilustração de João Turin ao representar também os símbolos do Paranismo: o pinheiro e o pinhão. Pode se afirmar que almejava-se por um leitor da revista cada vez mais adepto ao Paranismo, ou seja, viesse a se tornar um paranista, embora essa afirmação necessite de uma apuração mais rigorosa nas fontes primárias e secundárias, o que demandaria uma nova pesquisa para tratar do público leitor da revista.

Segundo Salturi (2009), a revista possuía uma excelente qualidade gráfica e editorial, principalmente nos elementos visuais da capa e das páginas internas, apresentando um estilo próprio numa articulação entre imagens e texto. Outro detalhe enunciado como característica gráfica da revista foram as "vinhetas ilustrativas" que nada mais eram as molduras usadas para separar os textos. "Além dessas vinhetas, desenhadas por João Turin, Frederico Lange de Morretes e Arthur Nísio, a revista também reproduzia desenhos, gravuras, esculturas e pinturas de vários artistas" (SALTURI, 2009, p.4) que ora apareciam para ilustrar textos ora vinham no tema principal. Os anúncios publicitários que aparecem ora no início ora no meio ora no final da revista permitiam manter financeiramente a circulação da mesma, o outro meio foi o incentivo estatal de Afonso Camargo, Presidente do Estado no período, que em contrapartida era feita uma apologia à política da época com publicações de desenhos e fotografias (SALTURI, 2009). Vale ressaltar que os artistas desse período faziam parte da mesma elite intelectual da sociedade paranaense e alguns dentre eles tiveram mais participação com suas obras publicadas na revista, como: João Turin, Alfredo Andersen, Lange de Morretes, Zaco Paraná, Arthur Nísio e Theodoro De Bona (SALTURI, 2009, p.6).

Outro marco na vida cultural curitibana veio na década de 1920 com a instalação de três livrarias: A Moderna, a Livraria Paloca e a Livraria Mundial (CARNEIRO, 2003). Como a cidade se tornava cada vez mais universitária, os livros e os periódicos exigiam do mercado um alto nível de qualidade. Segundo Carneiro (2003), o empresário Francisco Folch transferiu sua indústria e importou um novo equipamento litográfico para atender a demanda que aumentava. Isto é, devido à existência de uma clientela exigente houve uma acirrada competição entre os empresários que procuravam litógrafos especializados e máquinas industriais, favorecendo a qualidade das artes gráficas em Curitiba. Carneiro (2003) afirma que a revista Illustração Paranaense possuía um alto padrão de qualidade que manteve até $1930 \mathrm{com}$ a Revolução, "em consequência da grave crise que atingiu o Brasil e todo o país" (2003, p.69). De acordo com Araújo, "o litógrafo desse veículo é Marcos Leschaud" (2012, p.1060), considerado um excelente desenhista (A República, 1888 a 1930). 
Enfim, o movimento Paranista ou Paranismo exerceu papel fundamental na formação social e cultural de Curitiba e do Estado do Paraná como um todo, mas que seu principal meio de divulgação, a revista Illustração Paranaense, perdurou apenas por três anos. Mesmo assim, a revista foi capaz de "promover um arsenal de imagens visuais e mentais que pretendiam definir uma identidade local" (SALTURI, 2009, p.11), com a colaboração de muitos artistas e intelectuais colaboradores.

\section{AS CAPAS DA REVISTA}

A revista apresenta uma série de artistas plásticos muito influentes do período que tiveram participação significativa no layout interno da revista, como Frederico Lange de Morretes, Arthur Nísio, Alfredo Andersen, Theodoro de Bona e Zaco Paraná (SALTURI, 2009). Mas, caberá aqui a discussão sobre os elementos gráficos de composição da capa da revista desenvolvida por João Turin que é reproduzida nas capas das edições que vão de 1927 a 1930 com exceção do número 9 e 10 de 1930, e uma breve reedição em 1933.

Não podemos deixar de mencionar os acervos públicos que armazenaram a revista Illustração Paranaense que foram: a Biblioteca Pública do Paraná, a Casa da Memória e o Museu Paranaense, todas situadas na capital paranaense, Curitiba. Em todas elas, o periódico encontra-se no setor de Obras Raras devido sua datação e relevância para sociedade. Apesar de terem passado por um processo de conservação, pode-se perceber a ação do tempo nas suas edições, como: as extremidades rasgadas ou amassadas. Vale ressaltar que após esse mapeamento, a investigação culminou na confirmação que a coleção contida na Biblioteca Pública do Paraná era o acervo particular do João Batista Groff, diretor editorial (PILLOTO, 1976, p. 51).

As revistas foram encontradas no seu formato original, mas algumas edições foram encadernadas para que não fossem perdidas. Segundo a bibliotecária Márcia Moraes, da Biblioteca Romário Martins do Museu Paranaense, a encadernação era um hábito comum antigamente, pois era uma prática normal e habitual, embora não tenha registro de como essas revistas chegaram até o museu e mesmo se chegaram encadernadas ou se foram encadernadas no próprio museu como forma de manter a coleção num só espaço, conforme mostra a figura 1.

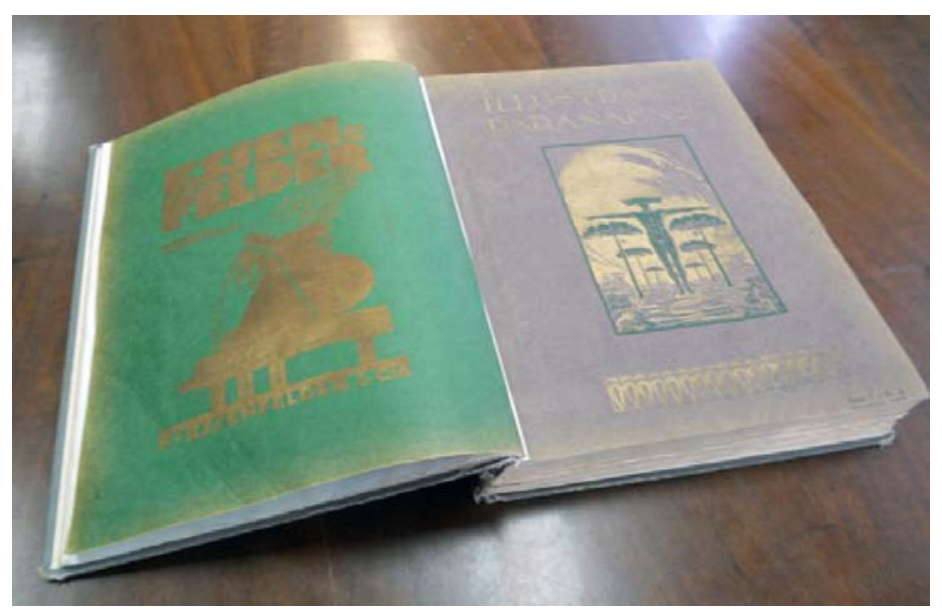

Figura 1 - Revista Illustração Paranaense encadernada. Fonte: Museu Paranaense 
As imagens das edições da revista foram cedidas pelo Museu Paranaense, mas infelizmente nem todas as obras estão completas. Os números que estão em branco tratam-se dos exemplares que não continham capa, somente o miolo com o conteúdo. No apêndice, pode-se observar as imagens com as fichas técnicas das capas da revista Illustração Paranaense distribuídas de acordo com o ano da edição.

\section{ANÁLISE DA IMAGEM}

Inicialmente, a ilustração de João Turin feita na primeira edição em 1927 é repetida nos outros números com alguns detalhes de diferenciação e no final de sua circulação, em 1930, cuja ilustração das capas foram substituídas por figuras políticas o qual caberia uma desconstrução que caracteriza essa mudança, mas que não será analisada no presente trabalho. Os símbolos utilizados na composição da capa da revista foram influenciados pelo movimento Paranista como foi comentado anteriormente. A estratégia de análise da capa da revista busca fundamento em Joly (1996), que percebe a imagem como equivalente a realidade sendo reconhecida, e observa a representação visual em três categorias de signos: "a "imagem" no sentido teórico do termo (icônicos, analógicos); signos plásticos (cores, formas, composição interna, textura) e também os signos lingüísticos (linguagem verbal)" (apud WITIKOSKI, 2009 , p. 125). Nesse contexto, deve-se decifrar a imagem de modo natural com os elementos que a constroem, pois o autor não tem o domínio da significação que é produzida (JOLY, 1996).

Tais argumentos dão base para compreensão da mensagem visual constituída em: mensagem plástica, mensagem icônica e mensagem linguística. Para melhor visualizar os signos visuais que compõem a mensagem visual foram escolhidas duas capas de 1929, como mostra a figura 2. Pois, a capa da edição $\mathrm{N}^{\circ} .1$ de 1927 se assemelha a ilustração das capas de $1927\left(\mathrm{~N}^{\circ}\right.$. 2), $1928\left(\mathrm{~N}^{\circ} .1,2,3,4,5,6,7,8,9,10,11\right.$ e 12) e 1929 ( $N^{\circ} .1,2$ e 3) com a diferenciação nas duas cores do suporte em papel de média qualidade, produzida em processo litográfico. A outra capa analisada será a edição de $\mathrm{N}^{\circ}$. 12 de 1929, apesar de ambas serem do mesmo ano possuem certa diferenciação na sua composição como veremos a seguir.
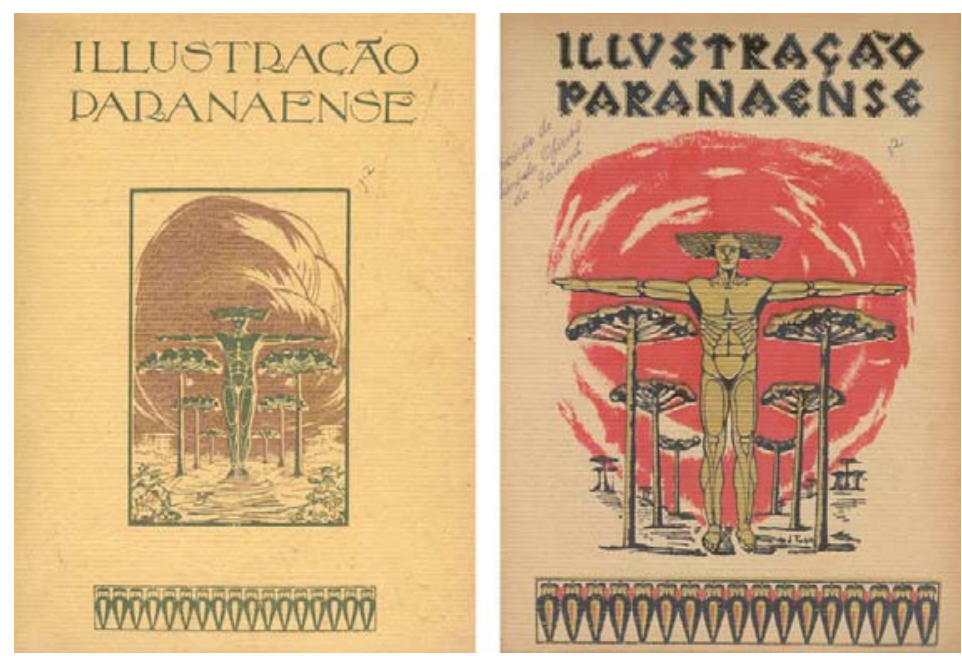

Figura 2 - Capas da llustração Paranaense, edição nº 1/2 de 1929 e n. 12 de 1929.

Fonte: Museu Paranaense 


\subsection{A mensagem plástica}

Os elementos plásticos das imagens são: formato, dimensão, cores, composição, enquadramento, tipografia e textura que fazem parte de uma significação da mensagem visual. Os signos plásticos preveem significados denotativos e conotativos que foram ferramentas para decifrar a imagem produzida pela capa.

O formato das capas é retangular na vertical que favorece a sensação de altura e ereto. A dimensão original da revista é de $23,5 \times 32 \mathrm{~cm}$, sendo a versão da revista encadernada de $22 \times 29,8 \mathrm{~cm}$, ou seja, houve um refilamento para que o livro obtivesse um acabamento ${ }^{2}$.

A estrutura básica nas duas primeiras edições e na sequência até a $\mathrm{N}^{\circ} .3$ de 1929 era de duas cores (fator 2/0), sendo que não possuía qualquer ilustração no verso. Neste caso, a impressão nas cores marrom e dourado que aparecem na primeira capa é destacada com a cor verde do próprio papel, esta refere à cor das árvores na ilustração. Vale ressaltar que o verde é uma cor de equilíbrio que remete a vegetação, a natureza, provavelmente tenha sido uma proposta dos paranistas para demonstrar a beleza natural do Paraná como exuberância que merece ser reconhecida como única no Brasil, o qual pertence ao Estado como algo próprio e específico. Nessa questão, os paranistas tentavam elucidar no imaginário dos paranaenses uma afeição maior pela terra, por meio da paisagem.

Nas duas primeiras edições, a impressão dessas cores também está presente na ilustração da capa onde as cores mais escuras concentram-se na representação do "homem", do pinheiro e no contorno, quanto aos demais elementos (céu, planta rasteira e terra) são entremeados com a cor dourada. Esse efeito perdura até a edição de número 8 de 1928, que posteriormente o dourado será substituído pelo bronze. A revista número 4 de 1929, a ilustração central não apresenta mais o contorno, o desenho é ampliado, mas perde alguns detalhes do céu e das plantas rasteiras que ficam próximas "aos pés do homem". Observa-se também na representação do homem que anteriormente as linhas a traço estavam vazias, uma vez que se concentrava no preenchimento com cor e a partir do número 7 e 8 de 1929, essa mesma representação evidencia as linhas a traço e o preenchimento, fazendo uso das duas técnicas favorecendo mais detalhes a ilustração. Embora, a borda que também continha na ilustração do pinhão também não se encontre mais, mas somente na edição de número 4 de 1929. Agora são utilizadas 3 (três) cores (preta, vermelho, dourado, azul e verde) no layout da capa, fazendo mais uso da cor preta.

O suporte, tipo de papel, utilizado nessas edições faz recordar o couchê com acabamento vergê $\hat{e}^{3}$ e com a gramatura de aproximadamente $180 \mathrm{~g} / \mathrm{m}^{2}$, embora a fibra não resistisse ao tempo com tendência para trincar, rachando a página. A tinta que dá a impressão de dourado estava desbotada, mas nota-se que esse esforço na época

\footnotetext{
2 Em artes gráficas é o processo de finalização de um produto gráfico (corte linear, encadernação, embalagem). (Disponível em: <http://www.plural.com.br/informativos glossario.php> acesso: 05/09/2013)

3 Tipo de acabamento que se dá ao papel cuja textura é constituída de linhas paralelas uniformemente $\begin{array}{lllll}\text { espaçadas, } \quad \text { visíveis contra luz. } & \text { (Disponível }\end{array}$ <http://www.plural.com.br/informativos glossario papel.php> acesso: 05/09/2013)
} 
significava a busca por um alto padrão de qualidade para que a revista tivesse uma "boa apresentação" perante a sociedade. Apesar de ter uma textura porosa que não oferece uma durabilidade do papel.

A composição do layout é centralizada, isto é, fixa-se no eixo central, promovendo um equilíbrio na leitura, onde cada coisa tem seu lugar e seu valor, permitindo a leitura por hierarquia das informações, de cima para baixo. 0 enquadramento da ilustração é retangular, devido seu contorno favorecer a visão de uma janela por onde se olha e obtém a paisagem construída.

A tipografia nas primeiras edições é mais elegante e demonstra certa influência europeia, uma vez que fazia parte do repertório cultural do autor, João Turin. Outra proposição assertiva seja que "a linguagem art nouveau influenciou muitos ilustradores, que tinham nos modernos periódicos franceses sua principal fonte de referência" (HALUCH, 2005, p. 104). Apesar de se aproximar da tipografia "OL Engravers Classic Roman" (ver figura 6), criada em 2009 por Dennis Ortiz-Lopez ${ }^{4}$ com a presença de serifas. A tipografia está presente desde a primeira edição, em 1927, e vai até o número 5 e 6 de 1929, quando ela passa a ser mais estilizada (ver figura 9). A tipografia da edição número 12 de 1929 foi mais elaborada no sentido de ter sido desenvolvida, pois não foi encontrado nenhum tipo semelhante. Isto leva a crer que provavelmente foi criada uma tipologia que será mais detalhada na mensagem linguística. Pois, esta outra permanece até sua reedição em 1933. Outro detalhe encontra-se no canto inferior direito que mostra o ano, o número, a data e o preço da publicação, mas ela só existe nas edições de 1927 e novamente na edição de 1930, N$^{\circ}$ 1,9 e 10.

\subsection{A mensagem icônica}

Cabe aqui associar certas ideias num processo de conotação para análise da mensagem icônica, conotadores de diversas ordens com o reconhecimento dos motivos: "usos socioculturais dos objetos, dos lugares, das posturas; citação e auto referência; figuras de retórica" (JOLY, 1996, p. 108). Nesse caso, o motivo principal encontra-se na ilustração feita por J. Turin, a figura de um homem de braços abertos que traça uma linha paralela com seus cabelos fazendo uma analogia a forma dos pinheiros que aparecem em segundo plano em perspectiva dando a ideia de um caminho. De modo geral, a visibilidade encontrada é a representação do homem, dos pinheiros, das plantas rasteiras, da nuvem e do pinhão, e a partir de cada uma que se buscará a mensagem icônica, pois trata-se de uma representação sinedótica, o qual "vemos partes de elementos que ali estão para designar o todo por contiguidade, da mesma maneira que a ausência da moldura nos levava plasticamente a construir o fora do campo da imagem" (JOLY, 1996, p. 104). Esse mesmo conceito se aplica a capa da revista que ora vem com a ilustração com uma espécie de contorno e na outra edição o contorno não aparece mais.

Com base no Paranismo, pode se perceber que a figura masculina faz uma analogia ao homem paranista cuja ilustração mostra o homem viril que demonstra

\footnotetext{
${ }^{4}$ Fonte: Disponível em: <http://www.myfonts.com/fonts/ortizlopez/ol-engravers-classic/> acesso 08/08/14.
} 
força ao realçar os traços da anatomia nos músculos. A pose do modelo (de braços erguidos) busca um equilíbrio entre as formas com a simetria e a ideia de contiguidade com os pinheiros aos lados. O mesmo oferece a direção dos cabelos que fazem lembrar a formação das copas dos pinheiros. Essa interpretação retoma aos objetos culturalmente codificados pelo Paranismo. O olhar concentra-se, principalmente, nessa figura que faz pensar sua postura, mesmo quando na outra edição não há mais o contorno retangular que fecha a ilustração (figura 3 e 4). A ilustração da capa foi assinada por João Turin e essa mesma assinatura permanece nas outras edições que possuem as adaptações. No entanto, essa afirmação implica que ele pode ser o autor da ilustração desde o início até suas alterações ou as edições com as adaptações tenha sido feita por algum litógrafo. Neste caso, não há nenhum documento que comprove que outra pessoa tenha feito tais adaptações. Embora, possivelmente tenha havido uma equipe de produção gráfica para obter a impressão no papel cujo resultado final está sendo analisado.

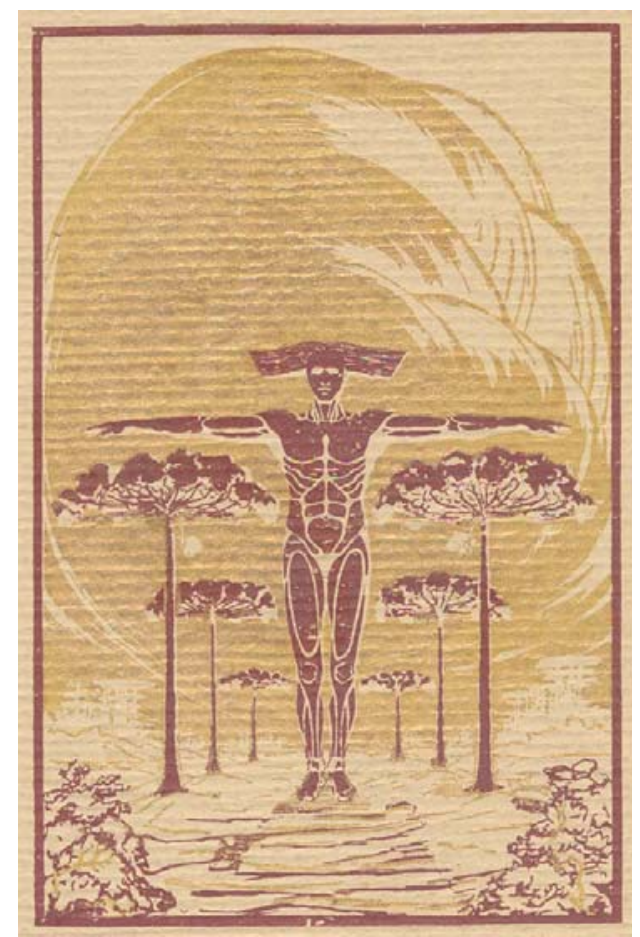

Figura 3 - Ilustração feita por João Turin, capa da edição n. 3 de 1929.

Fonte: Museu Paranaense

Os outros elementos que aparecem na ilustração giram em torno da figura masculina e leva o expectador a observar mais ainda a postura do homem. Nesse sentido, o pinheiro, como representação da natureza silvestre em harmonia com a composição, traz um ar de tranquilidade e remete as Araucárias ${ }^{5}$, pinheiros brasileiros que são dominantes na região Sul do Brasil, principalmente, no Paraná. A pequena planta rasteira desenhada no primeiro plano aparece sem muito foque, mas que se torna um contraste com os enormes pinheiros. Pode-se dizer que elas aparecem para favorecer os pinheiros como árvores predominantes na área territorial. Na centralidade que se encontra a figura do homem também surge um caminho cujos pinheiros estão

5 Fonte: Disponível em: <http://www.invivo.fiocruz.br/cgi/cgilua.exe/sys/start.htm?infoid=965\&sid=2> acessado em: 08/08/14 
lado a lado formando um fila, dando a ideia de profundidade pela perspectiva como se apresentam e, ao final, a cor que forma a nuvem finaliza o desenho. Outro detalhe fornecido pelo Paranismo foi o "clima ameno e semelhante aos climas europeus, foi amplamente utilizado para justificar uma suposta superioridade dos paranaenses em relação ao resto do Brasil" (BATISTELLA, 2012, p. 6). Desse modo, as nuvens ilustradas densamente representam esse diferencial do clima tropical encontrado em boa parte do país. Embora alguns detalhes, principalmente no primeiro plano (céu, planta rasteira e terra) não apareçam na outra reprodução da ilustração de Turin, permanece a mesma ideia de criar um paranista. Nesse caso, a representação do homem quando passa para o primeiro plano fica ainda mais evidente seu simbolismo, como pode ser visto na figura 4.

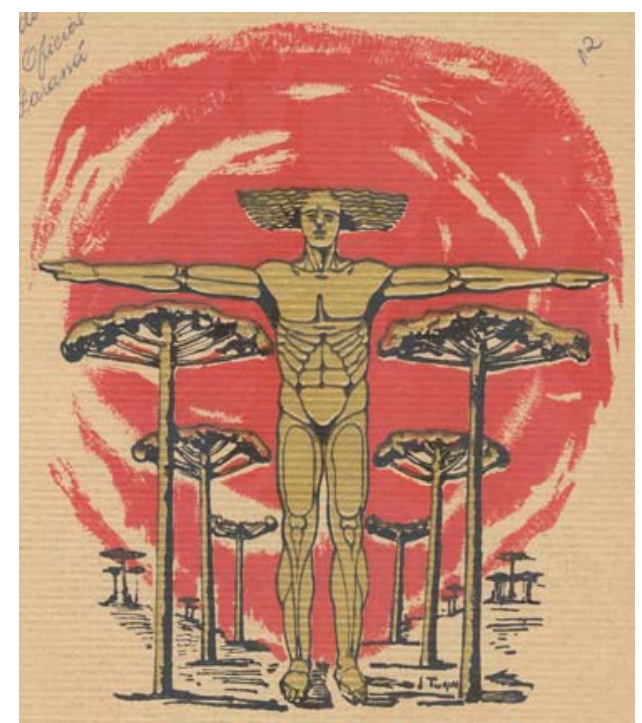

Figura 4 - Ilustração feita por João Turin, capa da edição n. 7 e 8 de 1929. Fonte: Museu Paranaense

Ao mesmo tempo em que há um espaço vazio entre o logotipo, a ilustração figurativa do "homem" e o rodapé de "pinhão", há uma pregnância da forma que provoca uma organização visual. O pinhão que é a semente do pinheiro faz alusão ao germinar de uma árvore que será grande, possivelmente, ao próprio ideário Paranista ao qual é promovido pela revista. Uma vez que ele aparece no rodapé num sistema de repetição numa justaposição quase não variável quanto a sua forma, mas sim quanto a sua cor no uso do preenchimento ou ficando a traço, como pode ser visto na figura 5.

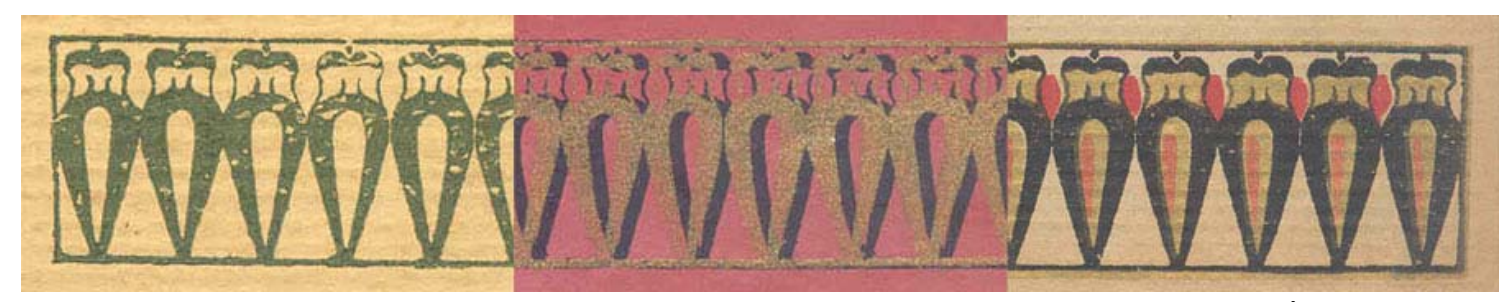

Figura 5 - Ilustração do rodapé feita por João Turin da capa da edição n. 1/2 de 1929, edição n. 1 de 1928 e edição n. 1 de 1930.

Fonte: Museu Paranaense

Apesar da complexidade da ilustração central da capa da revista, ela apresenta a categoria conceitual de minimidade, pois economiza elementos numa composição, 
utilizando o mínimo de unidades ou elementos para apresentar o essencial. O que favorece uma organização da forma, caracterizada da seguinte maneira: cabeçalho (tipologia), ilustração central (representação do homem com braços erguidos) e o rodapé (representação do pinhão repetido lado a lado).

As últimas edições de 1930, números 9 e 10, não apresenta mais a ilustração de J. Turin, ao invés, foi colocado a fotografia de rosto do General Plínio Tourinho, Comandante em chefe das forças revolucionárias do Paraná e Santa Catarina, e de Getúlio Vargas, chefe do Governo Provisório. Percebe-se que as técnicas utilizadas nessas edições não são mais as mesmas, provavelmente seja offset, usando somente a cor preta. $O$ suporte também é diferente dos anteriores, é mais liso, leve e acetinado. $O$ processo litográfico permitia que a ilustração fosse semelhante a cada número, permitindo variar suas cores como dita anteriormente. Segundo nota do Jornal "A República" (31/12/1929), a revista era impressa em oficinas próprias. Não há registros que apontem uma interferência política direta na ação do movimento Paranista representado pela revista nessas duas edições de 1930. Entretanto, foram as últimas edições que deram voz ao Paranismo. Pois, a reedição de 1933 foi comemorativa ao 79 Aniversário do Estado do Paraná, promovido pela Associação Paranaense de Imprensa, tratava apenas da Exposição Industrial ocorrida em 1932 e demais feitos culturais.

\subsection{A mensagem linguística}

A mensagem linguística divide em três tipos de mensagem: legenda, lista de endereços e precisão (JOLY, 1996, p. 110), que será visto o aspecto plástico. Nesse caso, a mensagem visual consiste desde a tipologia apresentada na capa da revista, o que poderíamos chamar de "imagem das palavras" e a diagramação que favorece a hierarquia das informações na composição do layout da capa. Apesar de inicialmente apresentar uma tipografia de espessura fina com serifa sinuosa, o efeito de sombra que aparece noutras edições constitui um apelo visual, pois favorece um destaque ao título da revista e representa a seriedade do periódico como porta-voz do Paranismo. Embora, o subtítulo "Mensário Paranista de Arte e Actualidades" que diz respeito ao conteúdo da revista, não aparece na capa nem como legenda e sim dentro dela, no miolo, na parte editorial. É possível afirmar que tenha sido proposital colocar apenas o título "Illustração Paranaense" para focar na ilustração tornando-a instigante ou também obter uma marca emblemática do Paranismo com a tipologia que pode ser reconhecida pelos leitores a cada edição.

A tipografia como aspecto plástico possui importância, devido ser imediatamente compreensível e dotada de significação da imagem visual, inclusive a escolha da cor que é associada ora com o contorno da ilustração que vem abaixo dela ora com a figura do homem. Em 1928, a tipografia que apresenta o logotipo "Illustração Paranaense" com efeito de sombra, isto é, utilizando a cor preta e colocando em sobreposição a cor dourada ao logotipo para dar ênfase a ela (figura 6). O mesmo nas edições cujo suporte (papel) possui uma coloração escura (vermelho e verde), enquanto que nas de coloração clara permanece apenas a cor dourada. Essa escolha possui tipos de associações interpretativas que estabelece uma mensagem distinta a cada edição. 


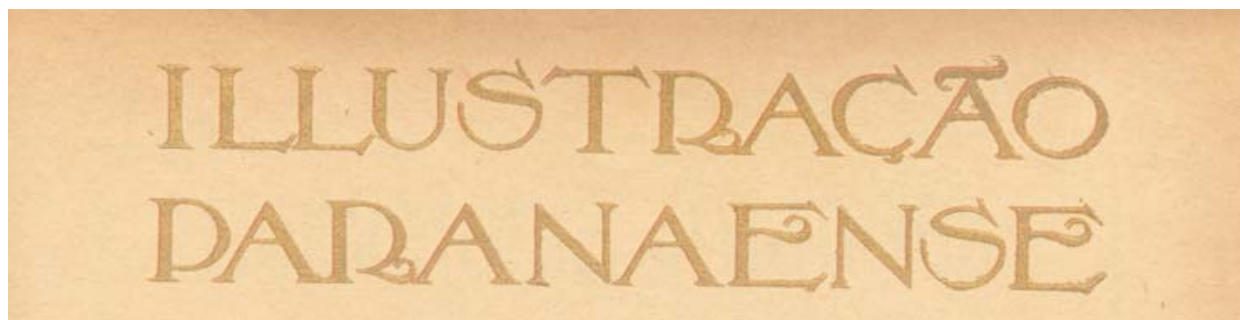

Figura 6 - Tipologia da llustração Paranaense feita por João Turin, capa da edição n. 3 de 1928.

Fonte: Museu Paranaense

O uso dessa tipografia continua até a edição número 5 e 6 de 1929, mas as cores variam conforme o contorno que fecha a ilustração no centro da capa. O mesmo efeito de sombra se aplica a ilustração do pinhão no rodapé da capa. Posteriormente, a tipografia se torna mais estilizada, com uma espessura mais grossa e marcante com os traços que seguem a sequência das formas, aumentando o apelo visual consideravelmente (ver figura 7). Isso parece significar que a escolha por esses caracteres fornece uma mensagem de força, provavelmente esteja ligado à maturidade com que o Paranismo recebeu com a criação do Centro Paranista.

A nova tipografia (figura 7) leva a crer que foi a criação de um logotipo específico para revista e, possivelmente, tenha tido alguma influência de João Turin que havia assinado a ilustração na capa da revista. Neste período, João Turin ainda estava ligado a Paris e o logotipo apresentado mesclava estilos que foram adequados as condições locais, como por exemplo a geometrização apresentada na ilustração do rodapé que representa o pinhão. Esta preocupação Paranista em ser cada vez mais autêntico tenha levado ao projeto de um logotipo aumentando a relação com o design gráfico. Percebem-se nela influências do estilo Art Déco que era um estilo gráfico da época, sendo que as fontes mais geométricas poderia ser a referência aos bordados ucranianos configurando em elementos decorativos. Observa-se que a construção do logotipo foi manual, pois a precisão nas linhas que circundam o tipo finaliza com pontos, como se fosse a "mancha" da tinta que encerra a arte. Enquanto que as parte mais grossas podem ser facilmente preenchidas. Neste caso, a cor escolhida também possui um contraste maior com relação ao suporte (coloração do papel).

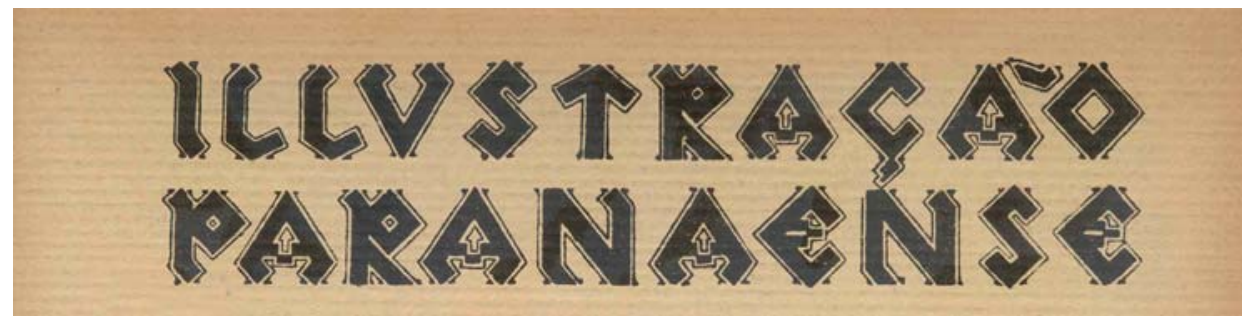

Figura 7 - Tipologia da llustração Paranaense feita por João Turin, capa da edição n. 12 de 1929.

Fonte: Museu Paranaense

Em síntese, a mensagem implícita na tipografia e nos demais signos plásticos acompanham a evolução do movimento Paranista ocorrida no Estado do Paraná, fazendo crescente o ideário Paranista por meio dos aspectos plásticos. Além de 
construir uma retórica da imagem com a ilustração de J. Turin, principalmente, no ato de convencer o leitor a apreciar o Paranismo como uma realidade a ser vivida.

\section{CONCLUSÃO}

A revista "Illustração Paranaense" teve repercussão na sociedade paranaense que levava o ideário Paranista em todas as suas folhas, bem como na mensagem visual. Infelizmente, a circulação da revista foi interrompida com a Revolução de 1930 e com a reedição em 1933, que não teve o mesmo rigor de qualidade gráfica e editorial (SALTURI, 2009). As capas analisadas se restringiam a uma análise formal e simbólico, e não uma análise de contextualização histórica cuja proposta metodológica seria outra, que não foi o caso. Mas, com essa aproximação do campo do design gráfico com a literatura paranaense abre-se a discussão sobre a mensagem plástica produzida por profissionais daquele período que se utilizaram das técnicas e tecnologias disponíveis para obter resultados satisfatórios.

Como observado, o movimento Paranismo defendeu um contexto racial europeizado que foi assumido na história oficial escrita pelo historiador Romário Martins. A revista como um dos principais difusores também assumiu na sua capa esse ideário ao apresentar um homem que se assemelhava visualmente com o homem vitruviano, de Leonardo da Vinci, cujas bases são da proporção áurea que apresentaria um modelo ideal de homem. Isto é, possivelmente a ilustração do homem feita por J. Turin apresentaria o ideal do homem paranaense baseado no Paranismo. As demais representações visuais - os pinheiros, as plantas rasteiras, a nuvem (densa) e o pinhão - sustentavam o sentido de lugar com intuito de as tornar "figuras de retórica" (JOLY, 1996), como por exemplo, a mata das Araucárias (pinheiros) que faz parte da vegetação sulista tendo maior concentração no Estado do Paraná, reforça o local que a revista e o próprio movimento estão situados. Afinal, é através da imagem que se produz um sentindo e uma atitude interpretativa (WITIKOSKI, 2009).

Com isso, percebe-se que a mensagem visual é construída a partir da interação de diferentes ferramentas e signos, como apresentada: plástico, icônico e linguístico (JOLY, 1996, p. 113). Num trabalho de associações com o saber cultural e sociocultural do expectador, bem como o contexto interpretativo demonstrado com a questão histórica que acompanha a análise para melhor entendê-la, é possível visualizar a significação com relação da interpretação que se dá aos elementos compositivos. Fica evidente na mensagem plástica como o Paranismo influenciou diretamente na composição do layout da capa da revista para favorecer a mensagem conotativa do paranista ao leitor. Com isso, o design gráfico evoca uma mensagem visual construída que permite ser analisada e entendida como uma estratégia que nortearam sua significação final e a influência conotativa do Paranista, principalmente no diz respeito na relação de imagem e texto. Tal pesquisa favorece a abertura de mais estudos no campo do design gráfico no intuito de promover a reconstrução de memórias gráficas paranaenses.

\section{REFERÊNCIAS}

ARAÚJO, Adalice Maria de. Dicionário das Artes plásticas no Paraná. Vol. 2. Curitiba: Edição do autor, 2012. 
BATISTELLA, Alessandro. O Paranismo e a invenção da identidade paranaense. Revista Eletrônica História em Reflexão. Vol. 06. Nº 11 - UFGD - Dourados. Jan/Jun. 2012.

CARNEIRO, Newton. As artes gráficas em Curitiba. In: Páginas Escolhidas: literatura. Edição alusiva aos 150 anos da criação Política do Paraná. Vol. Il. Curitiba: Assembleia Legislativa do Paraná, 2003.

CERBINO, Ana Luiza e CERBINO, Beatriz. O design das páginas da Revista Rio. $9^{\circ}$ Congresso Brasileiro de Pesquisa e Desenvolvimento em Design. São Paulo: Blüsher e Universidade Anhembi Morumbi, 2010. ISBN: 978-85-212-0566-1

CERBINO, Ana Luiza. Memória e modernidade gráfica na Revista Rio. $10^{\circ}$ Congresso Brasileiro de Pesquisa e Desenvolvimento em Design. São Luís (MA), 2012.

GOMES FILHO, João. Gestalt do objeto: sistema de leitura visual da forma, 7. Ed. São Paulo: Escrituras Editora, 2004.

HALUCH, Aline. A Maçã e a renovação do design editorial na década de 1920. (p. 96 a 123). In: CARDOSO, Rafael (org.). O Design Brasileiro antes do design: Aspectos da história gráfica, 1870 - 1960. São Paulo: Cosac Naify, 2005.

JOLY, Martine. Introdução à análise da imagem. Tradução: Marina Appenzeller. Campinas, SP: Papirus, 1996.

MENESES, Ulpiano T. Bezerra. Fontes visuais, Cultura Visual, História Visual: Balança provisório, propostas cautelares. Revista Brasileira de História. São Paulo, V. 23. N 45, pp. 11-36. 2003.

PILLOTO, Osvaldo. Cem anos de imprensa no Paraná (1854-1954). Edição do Instituto Histórico, Geográfico e Etnográfico Paranaense. Curitiba: Estante Paranista, Ano I - $\mathrm{N}^{\circ}$ $1,1976$.

PRODANOV, C. C. Metodologia do trabalho científico [recurso eletrônico]: métodos e do trabalho acadêmico. $2^{\circ}$. ed. Novo Hamburgo: Feevale, 2013.

SALTURI, Luis Afonso. Arte e sociedade na Illustração Paranaense. I Seminário Nacional Sociologia e Política. UFPR. 2009. ISSN 2175-6880 (OnLine).

TURIN, Elisabete. A arte de João Turin. Campo Largo, PR: Ingra, 1998.

WITIKOSKI, Alan Ricardo. Design, Cultura e Tecnologia nos rótulos de Cachaça da cidade de Curitiba nas décadas de 1950 e 1960. Curitiba, PR: Dissertação de Mestrado - UTFPR, 2009.

PERIÓDICO

A Divulgação, Curitiba, PR. Fevereiro a Março, 1948 (p. 37 a 41). 
A República: órgão do Partido Republicano Paranaense (1888 a 1930). Curitiba, 7 de maio de 1930. (Fonte: Disponível em: <http://memoria.bn.br/hdb/periodo.aspx> Acesso em: 06/09/2013)

\section{ENTREVISTA}

Entrevista com a Bibliotecária Jussara Ferreira Reinert, Fundação Cultural de Curitiba e a Coordenadora do setor de Documentação e Obras Raras da Casa da Memória. Curitiba, 17 de julho de 2013.

Entrevista com a Bibliotecária Márcia Moraes, Biblioteca Romário Martins do Museu Paranaense. Curitiba, 18 de julho de 2013.

Entrevista com a Bibliotecária Josefina Palazzo Ayres, Divisão de Documentação Paranaense da Biblioteca Pública do Paraná. Curitiba, 27 de agosto de 2013. 


\section{APÊNDICE}

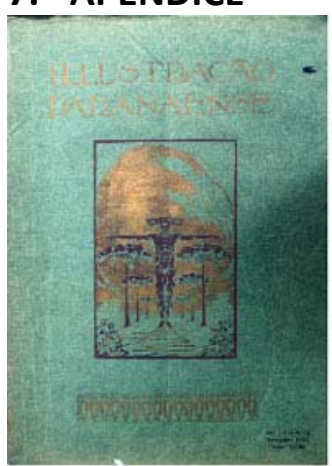

$\mathrm{N}^{\circ} \mathrm{O}^{*}$

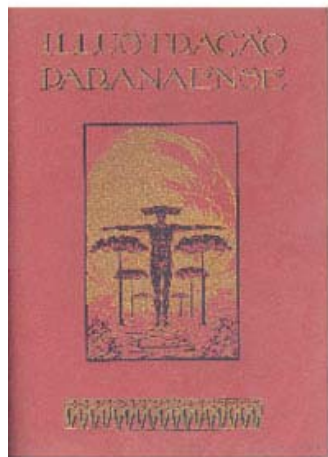

$\mathrm{N}^{\circ} 01$

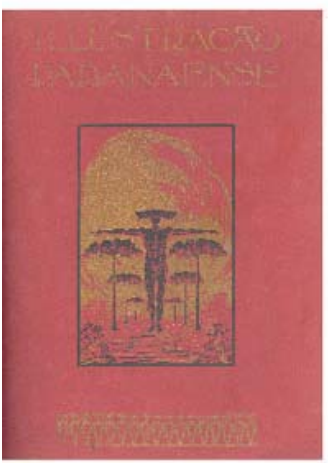

$\mathrm{N}^{\circ} 04$

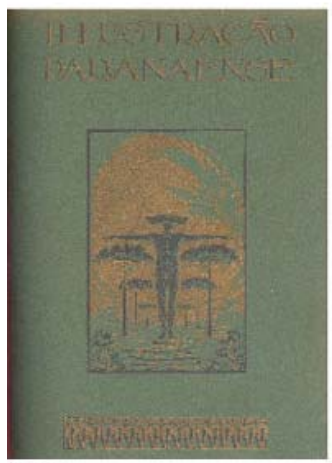

$\mathrm{N}^{\circ} 08$

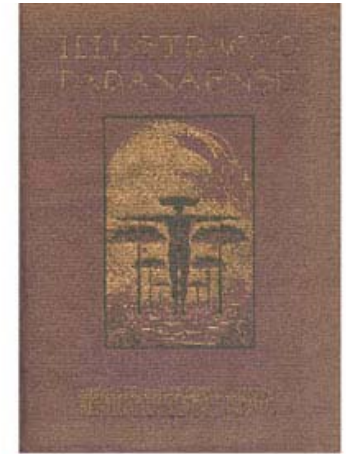

$\mathrm{N}^{\circ} 02$

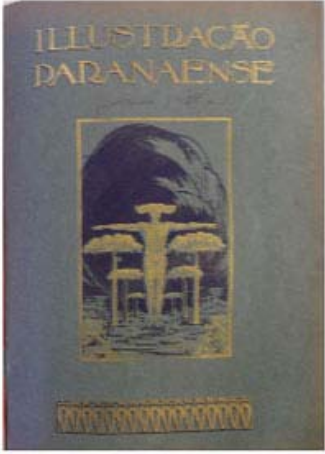

$\mathrm{N}^{\circ} \mathrm{O} 2^{\star *}$

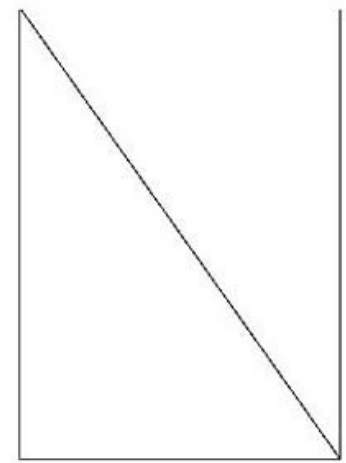

$\mathrm{N}^{\circ} 05$

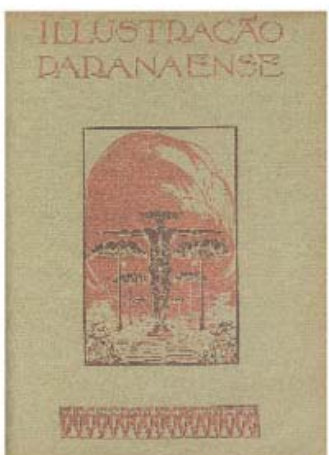

$\mathrm{N}^{\circ} 09$

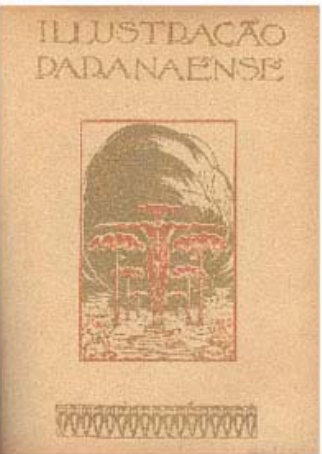

Ficha técnica

Título do Periódico:

Illustração Paranaense

Título Original:

Illustração Paranaense

Local e editor: J. B.

Groff

Data: 1928

Volume/Ano: 2

Fonte: Museu

Paranaense

** Foto: Carla Batista

\section{$\mathrm{N}^{\circ} \mathrm{O3}$}

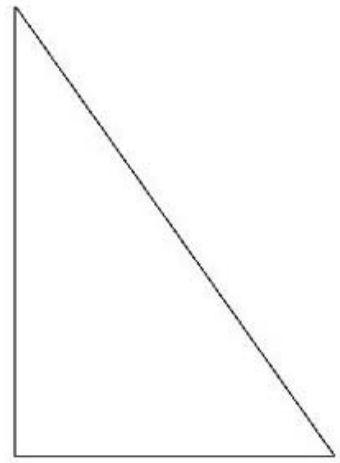

$\mathrm{N}^{\circ} 06$

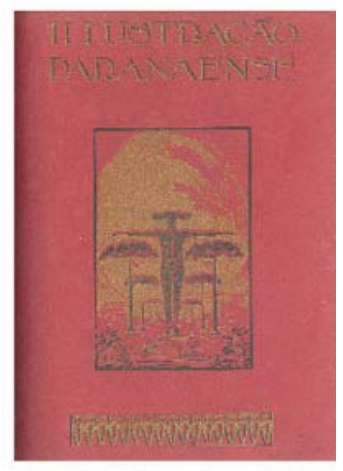

$\mathrm{N}^{\circ} 07$

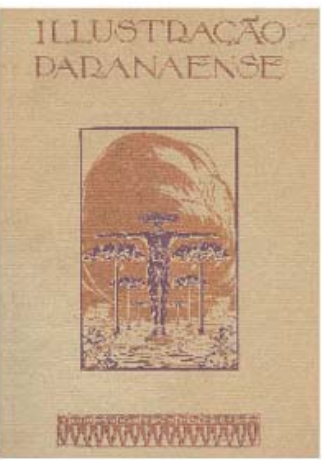

II 1. US IDACAO

DADANALNST

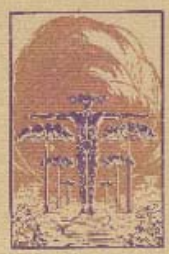

Thownowawe

$N^{\circ} 10 \mathrm{e} 11$
$\mathrm{N}^{\circ} 12$ 


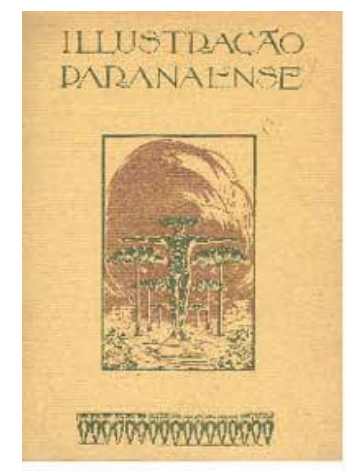

$\mathrm{N}^{\circ} 01$ e 02

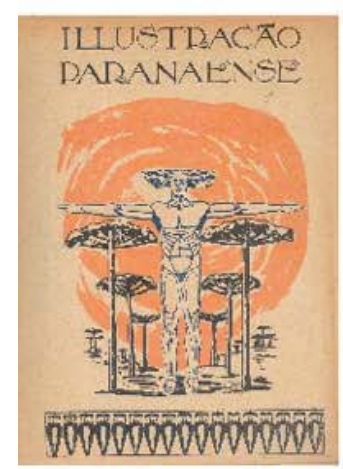

$\mathrm{N}^{\circ} 05$ e 06

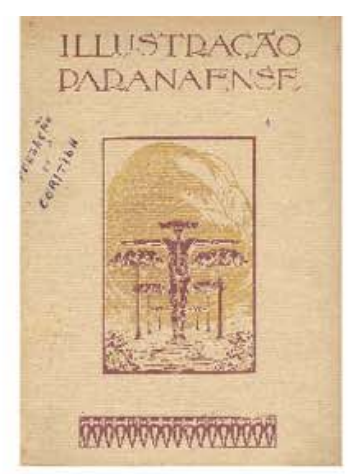

$\mathrm{N}^{\circ} 03$

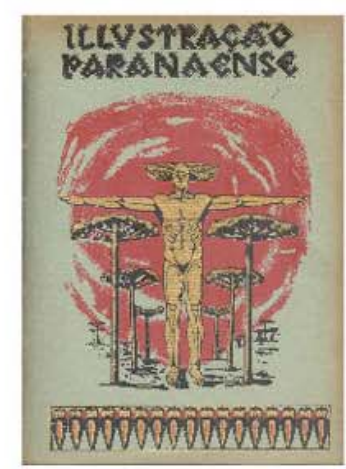

$\mathrm{N}^{\circ} 07$ e 08

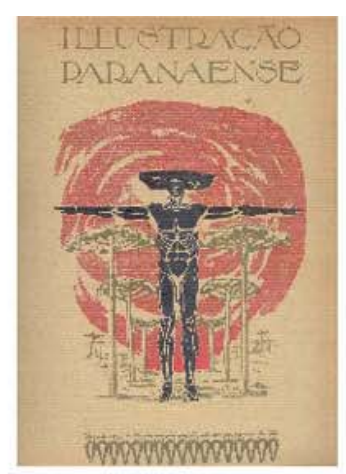

$\mathrm{N}^{\circ} \mathrm{O} 4$
Ficha técnica

Título do Periódico:

Illustração Paranaense

Título Original:

Illustração Paranaense

Local e editor: J. B.

Groff

Data: 1929

Volume/Ano: 3

Fonte: Museu

Paranaense

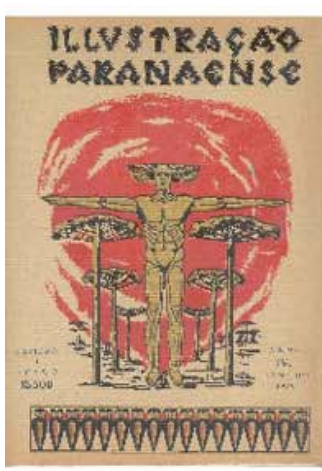

$\mathrm{N}^{\circ} 01$

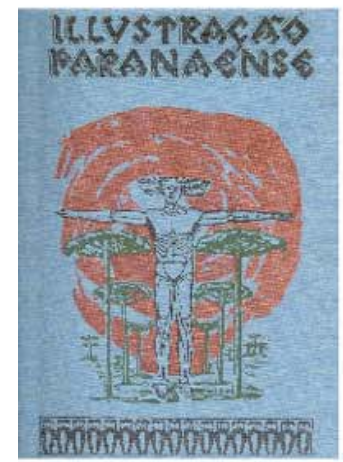
$\mathrm{N}^{\circ} \mathrm{O} 3$

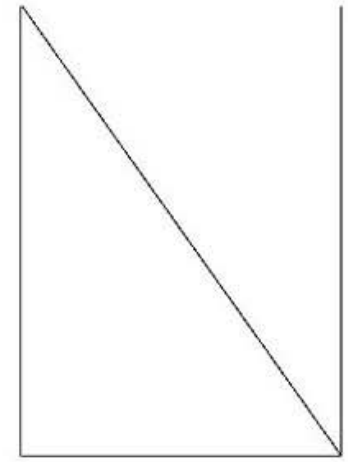

$\mathrm{N}^{\circ} \mathrm{O} 2$

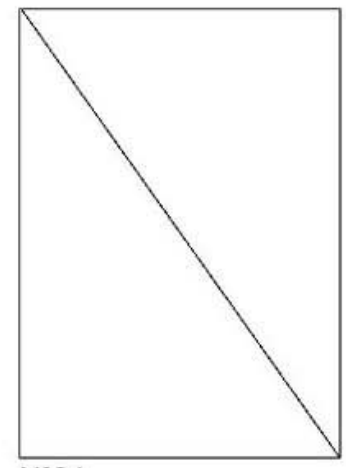

$\mathrm{N}^{\circ} 04$

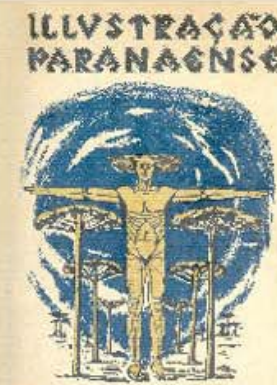

nominomomom

$\mathrm{N}^{\circ} 08$ a 11

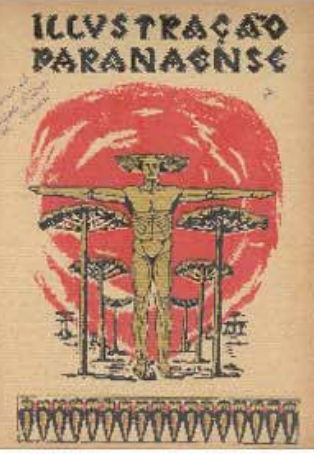

$N^{\circ} 12$
Ficha técnica

Título do Periódico:

Illustração Paranaense

Título Original:

Illustração Paranaense

Local e editor: J. B.

Groff

Data: 1930

Volume/Ano: 4

Fonte: Museu

Paranaense

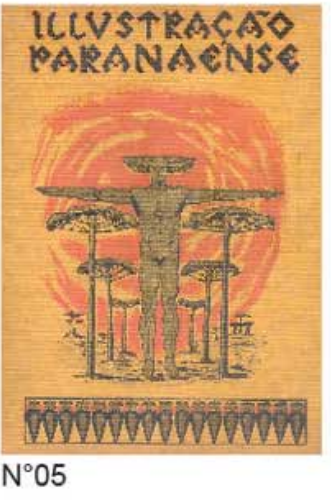

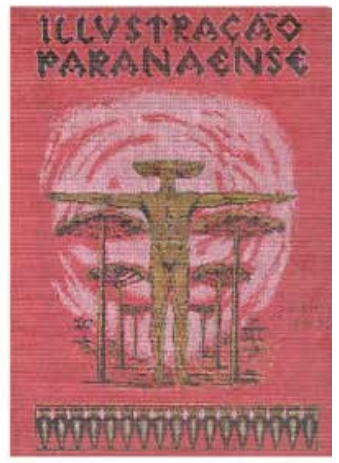

$\mathrm{N}^{\circ} 06$ 


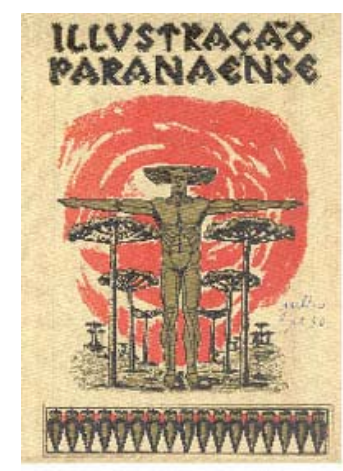

$\mathrm{N}^{\circ} 07$

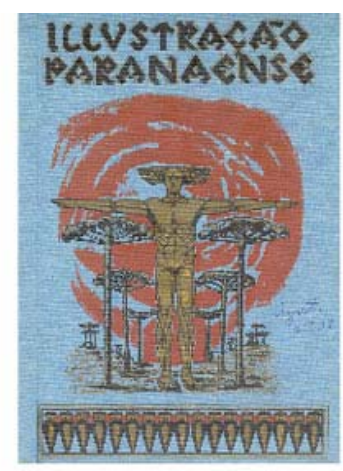

$\mathrm{N}^{\circ} 08$

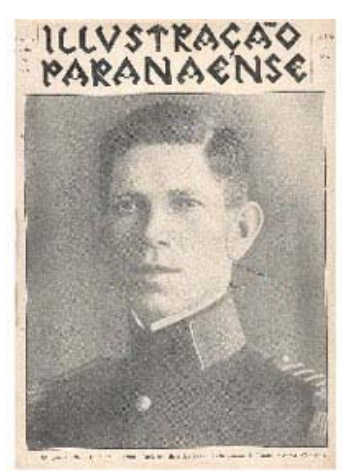

$\mathrm{N}^{\circ} 09$

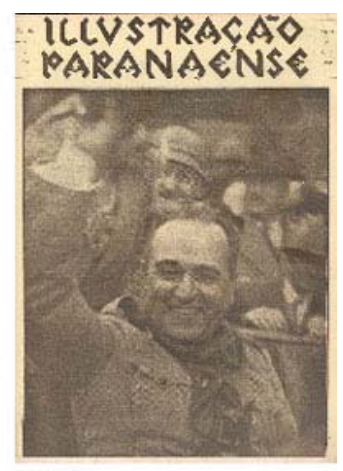

$N^{\circ} 10$

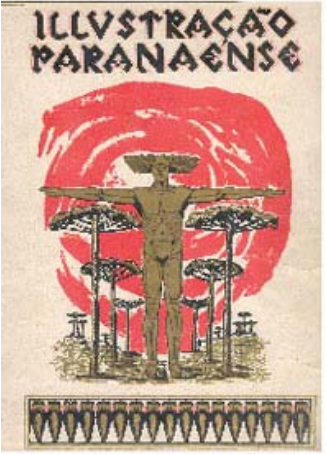

Ficha técnica

Título do Periódico:

Illustração Paranaense

Título Original:

Illustração Paranaense

Local e editor: J. B.

Groff

Data: 1933

Volume/Ano: 5

Fonte: Museu

Paranaense 